\title{
Exogenous expression of the glycosyltransferase LARGE1 restores a- dystroglycan matriglycan and laminin binding in rhabdomyosarcoma
}

Daniel Beltrán ${ }^{1}$, Mary E. Anderson ${ }^{1}$, Narendra Bharathy², Teagan P. Settelmeyer², Matthew N. Svalina², Zia Bajwa², John F. Shern ${ }^{3}$, Sakir H. Gultekin ${ }^{4}$, Marco A. Cuellar ${ }^{1}$, Takahiro Yonekawa', Charles Keller ${ }^{2^{*}}$ and Kevin P. Campbell ${ }^{1 *}$ (D)

\begin{abstract}
Background: a-Dystroglycan is the highly glycosylated component of the dystrophin-glycoprotein complex (DGC) that binds with high-affinity to extracellular matrix (ECM) proteins containing laminin-G-like (LG) domains via a unique heteropolysaccharide [-GlcA-beta1,3-Xyl-alpha1,3- $]_{n}$ called matriglycan. Changes in expression of components of the DGC or in the O-glycosylation of a-dystroglycan result in muscular dystrophy but are also observed in certain cancers. In mice, the loss of either of two DGC proteins, dystrophin or a-sarcoglycan, is associated with a high incidence of rhabdomyosarcoma (RMS). In addition, glycosylation of a-dystroglycan is aberrant in a small cohort of human patients with RMS. Since both the glycosylation of a-dystroglycan and its function as an ECM receptor require over 18 post-translational processing enzymes, we hypothesized that understanding its role in the pathogenesis of RMS requires a complete analysis of the expression of dystroglycan-modifying enzymes and the characterization of adystroglycan glycosylation in the context of RMS.
\end{abstract}

Methods: A series of cell lines and biopsy samples from human and mouse RMS were analyzed for the glycosylation status of a-dystroglycan and for expression of the genes encoding the responsible enzymes, in particular those required for the addition of matriglycan. Furthermore, the glycosyltransferase LARGE1 was ectopically expressed in RMS cells to determine its effects on matriglycan modifications and the ability of a-dystroglycan to function as a laminin receptor.

(Continued on next page)

\footnotetext{
*Correspondence: charles@cc-tdi.org; kevin-campbell@uiowa.edu

${ }^{2}$ Children's Cancer Therapy Development Institute, 12655 SW Beaverdam Road W, Beaverton, OR 97005, USA

'Department of Molecular Physiology and Biophysics, Department of Neurology, Howard Hughes Medical Institute, University of lowa Roy J. and Lucille A. Carver College of Medicine, 4283 Carver Biomedical Research Building, 285 Newton Road, lowa City, IA 52242-1101, USA

Full list of author information is available at the end of the article
}

(c) The Author(s). 2019 Open Access This article is distributed under the terms of the Creative Commons Attribution 4.0 International License (http://creativecommons.org/licenses/by/4.0/), which permits unrestricted use, distribution, and reproduction in any medium, provided you give appropriate credit to the original author(s) and the source, provide a link to the Creative Commons license, and indicate if changes were made. The Creative Commons Public Domain Dedication waiver (http://creativecommons.org/publicdomain/zero/1.0/) applies to the data made available in this article, unless otherwise stated. 
(Continued from previous page)

Results: Immunohistochemistry and immunoblotting of a collection of primary RMS tumors show that although adystroglycan is consistently expressed and glycosylated in these tumors, a-dystroglycan lacks matriglycan and the ability to bind laminin. Similarly, in a series of cell lines derived from human and mouse RMS, a-dystroglycan lacks matriglycan modification and the ability to bind laminin. RNAseq data from RMS cell lines was analyzed for expression of the genes known to be involved in a-dystroglycan glycosylation, which revealed that, for most cell lines, the lack of matriglycan can be attributed to the downregulation of the dystroglycan-modifying enzyme LARGE1. Ectopic expression of LARGE1 in these cell cultures restored matriglycan to levels comparable to those in muscle and restored high-affinity laminin binding to a-dystroglycan.

Conclusions: Collectively, our findings demonstrate that a lack of matriglycan on a-dystroglycan is a common feature in RMS due to the downregulation of $L A R G E 1$, and that ectopic expression of $L A R G E 1$ can restore matriglycan modifications and the ability of a-dystroglycan to function as an ECM receptor.

Keywords: Dystroglycan, Matriglycan, LARGE1, Rhabdomyosarcoma, Laminin,

\section{Background}

Dystroglycan is a ubiquitously expressed extracellular matrix (ECM) receptor and plays key roles in the formation and maintenance of many tissues [1]. In skeletal muscle, dystroglycan is part of the dystrophin-glycoprotein complex (DGC), which establishes a continuous link between the laminin-G-like (LG) domain-containing ECM proteins and the intracellular cytoskeleton. The key role that the DGC plays in muscle function is highlighted by the fact that mutations in almost any gene encoding one of its components can cause muscular dystrophy [2]. Furthermore, mutations in a single component of the DGC can result in instability and loss of the entire complex, highlighting the requirement for the complex to be intact.

Similarly, loss of dystroglycan function has been associated with human pathologies, including muscular dystrophy with or without various degrees of brain and eye defects [1]. Dystroglycan is synthesized as a single precursor that is subsequently cleaved into two subunits that remain tightly but non-covalently linked: the cell surface-associated $\alpha$-dystroglycan and the membranespanning $\beta$-dystroglycan. $\alpha$-Dystroglycan functions as a receptor for several LG domain-containing basement membrane proteins, including laminin [3-5], perlecan [6], agrin [7], and Slit [8], whereas $\beta$-dystroglycan binds to proteins involved in cytoskeleton organization (dystrophin and utrophin) [9-11]. $\alpha$-Dystroglycan requires extensive glycosylation and post-translational processing in order to bind to its extracellular ligands. This functional glycosylation consists of the unique heteropolysaccharide [-GlcA-beta1,3-Xyl-alpha1,3-]n called matriglycan, which has been reported only on $\alpha$-dystroglycan and binds with high-affinity to ECM proteins that contain LG domains. In humans, mutations in any of the genes coding for the glycosyltransferases involved in this process can lead to a spectrum of syndromes known as secondary dystroglycanopathies. These conditions are characterized by an absence or reduction in the matriglycan modification on $\alpha$-dystroglycan and by muscular dystrophy with or without brain and eye defects.

We and others have demonstrated that glycosylation of $\alpha$-dystroglycan is also compromised in a wide variety of cancers, and that this defect correlates with poor prognosis [12-16]. An analysis of knockout mouse models for two of the DGC components, dystrophin $(m d x)$ and $\alpha$-sarcoglycan, demonstrated that primary defects in the DGC are sometimes associated with the formation of rhabdomyosarcomas (RMS) [17]. Specifically, among aged ( $>1$ year old) mice deficient for dystrophin $(m d x)$ or $\alpha$-sarcoglycan, $21 \%(32 / 150)$ and $5 \%(4 / 80)$ of mice developed such tumors, respectively. Mdx-derived tumors display both cellular and molecular characteristics of embryonal rhabdomyosarcoma (eRMS) and almost no characteristics of alveolar rhabdomyosarcoma (aRMS).

Biochemical evidence supporting the involvement of $\alpha$-dystroglycan in RMS comes from a manuscript reporting on five RMS tumors, which found the expression of $\alpha$-dystroglycan to be reduced or absent while that of $\beta$-dystroglycan was normal [18]. Parallel studies of human RMS have indicated that dystrophin may have roles as a tumor suppressor [19].

In the study described here, we expand on the above-described investigations by describing a functional role for dystroglycan in RMS, and begin to elucidate the molecular mechanism underlying its altered function. Analysis of a microarray panel containing eRMS and aRMS tissue revealed that matriglycan levels on $\alpha$-dystroglycan are reduced in both sample types. Similarly, analysis of cell lines derived from human and mouse RMS shows that in a subset of these cell lines, $\alpha$-dystroglycan lacks matriglycan, and that this is accompanied by reduced expression of the glycosyltransferase LARGE1. Lastly, we found that ectopic expression of LARGE1 in RMS cells restored both the matriglycan modification of $\alpha$-dystroglycan and the ability of 
$\alpha$-dystroglycan to bind laminin, demonstrating that the loss of LARGE1 expression causes the lack of matriglycan and a loss of high-affinity laminin binding in RMS.

\section{Methods}

\section{Experimental replicates}

All experiments were repeated in the laboratory three times. Data reported are representative.

\section{Cell culture}

Primary cells from genetically engineered mouse aRMS samples were cultured as previously described [20, 21]. The collection of tumors and the culture of primary cells from human RMS were performed under an IRB approved protocol from Oregon Health \& Science University. In brief, for each culture, the tumor was minced and digested with collagenase $(10 \mathrm{mg} / \mathrm{ml})$ overnight at $4{ }^{\circ} \mathrm{C}$. The dissociated cells were then incubated in Dulbecco's modified eagle's media (DMEM) supplemented with $10 \%$ fetal bovine serum (FBS) and 1\% penicillin-streptomycin in $5 \% \mathrm{CO}_{2}$ at $37^{\circ} \mathrm{C}$. Experiments were performed at or before passage 10 .

\section{Adenovirus-mediated gene transfer}

The human genes that code for dystroglycan, POMT1, POMT2, POMGNT1, POMGNT2, B3GALNT2, POMK, LARGE1, LARGE2, B3GNT1, Fukutin, FKRP, ISPD, and TMEM5 were cloned into replication-deficient adeno-viral (Ad5) vectors. Adenovirus was generated by the Viral Vector Core at the University of Iowa. The generation of Ad5 constructs was described previously [5]. Cancer cells were grown to $70-80 \%$ confluency in 48 -well or $10 \mathrm{~cm}$ plates, and were infected with Ad5 constructs at an MOI of 3 in the corresponding complete medium $48 \mathrm{~h}$ after infection.

\section{CDNA synthesis and real-time PCR}

Total RNA was extracted from cells in culture using the RNeasy isolation kit (Qiagen). First-strand complementary DNA (cDNA) was synthesized from total RNA using the AMV reverse transcriptase (Roche) and a combination of random hexamers and polyA primers, according to the manufacturer's instructions. Each of the target genes was amplified in real-time from cDNA using oligonucleotides specific to that gene (sequences and conditions available upon request), with 28S-RNA,

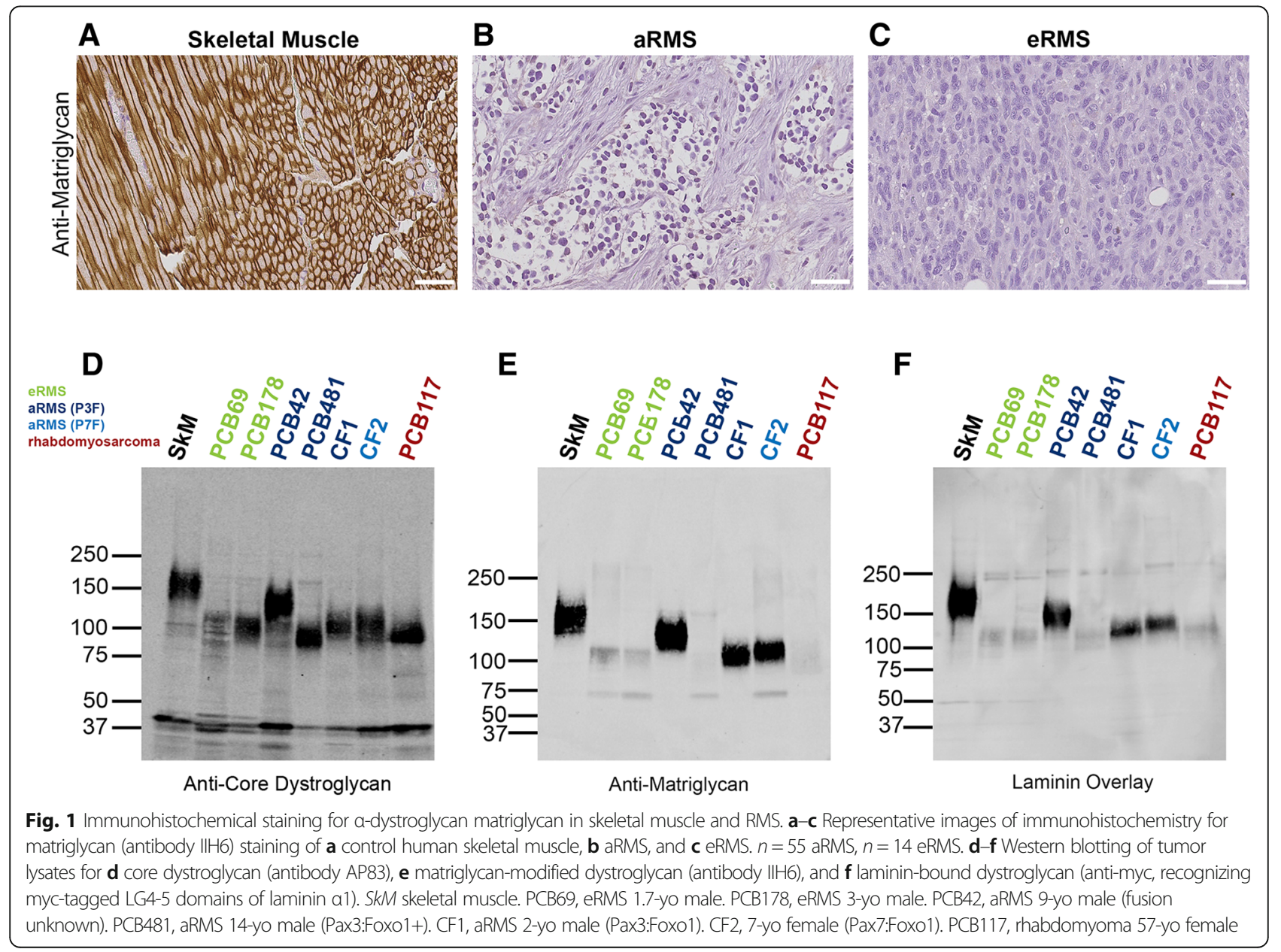


Rpl27, and Rpl4 used as the normalization controls. cDNA levels were determined using SYBR green in a MyiQ rt-PCR detection system (BioRad). All samples were run in triplicate.

\section{Western blotting}

Proteins were extracted from cultured cells using lysis buffer $(50 \mathrm{mM}$ Tris $\mathrm{pH} 7.6,150 \mathrm{mM} \mathrm{NaCl}, 1 \%$ Triton, and protease inhibitor cocktail in 1x PBS). Insoluble material was removed by centrifugation at $12,000 \times g$ for $15 \mathrm{~min}$. The solubilized supernatant was added to $200 \mu \mathrm{l}$ of wheat germ agglutinin (WGA) slurry (Vector Labs) and the samples were rotated overnight at $4{ }^{\circ} \mathrm{C}$. The pelleted WGA beads were washed three times with $1 \mathrm{ml}$ TBS containing $0.1 \%$ Triton X-100. After the final wash, $250 \mu \mathrm{l}$ of loading buffer (loading sample buffer (LSB)) was added to the beads. The samples were heated to $99^{\circ}$ C for 10 min before loading into 3-15\% SDS-PAGE gels, and protein was subsequently transferred to polyvinylidene fluoride (PVDF) membranes, which were subsequently blocked in $2 \%$ nonfat dried milk in TBST buffer (50 mM Tris pH 8.0, $150 \mathrm{mM} \mathrm{NaCl,} \mathrm{0.05 \%} \mathrm{Tween} \mathrm{20).}$ All antibodies were diluted in the same buffer that was used for blocking. Membranes were washed in TBST buffer. Blots were developed with IR-conjugated secondary antibodies (Pierce Biotechnology, Rockford, IL) and scanned using an Odyssey infrared imaging system
(LI-COR Bioscience, Lincoln, NE). $\alpha$-Dystroglycan and $\beta$-dystroglycan core proteins were detected using antibody AF6868, and matriglycan was detected using antibody IIH6 [22, 23]. Electrophoresis was performed by standard SDS-PAGE methods. Precision Plus Protein ${ }^{\mathrm{mm}}$ (BioRad) was used as the molecular weight marker for Western blot analysis.

\section{Laminin overlay assay}

Ligand overlay assays were performed on membranes using mouse Engelbreth-Holm-Swarm (EHS) laminin (Sigma-Aldrich) [24]. Briefly, PVDF membranes were blocked in laminin binding buffer (LBB: $10 \mathrm{mM}$ triethanolamine, $140 \mathrm{mM} \mathrm{NaCl}, 1 \mathrm{mM} \mathrm{MgCl}, 1 \mathrm{mM} \mathrm{CaCl}_{2}, \mathrm{pH}$ 7.6) containing $3 \%$ bovine serum albumin (BSA) followed by incubation with laminin overnight at $4{ }^{\circ} \mathrm{C}$ in $\mathrm{LBB}$. Membranes were washed and incubated with anti-laminin antibody (L9393, Sigma-Aldrich, 1:100) followed by Licor dye-conjugated donkey anti-rabbit IgG.

\section{Solid-phase assay}

WGA eluates were diluted 1:50 in TBS and coated on polystyrene ELISA microplates (Costar) overnight at $4{ }^{\circ} \mathrm{C}$. Plates were washed in LBB and blocked for $1 \mathrm{~h}$ in $3 \%$ BSA in LBB. Mouse EHS laminin was diluted in LBB and applied for $2 \mathrm{~h}$. Wells were washed with $3 \%$ BSA in LBB and incubated for 30 min with anti-laminin antibody (L9393, Sigma-Aldrich,

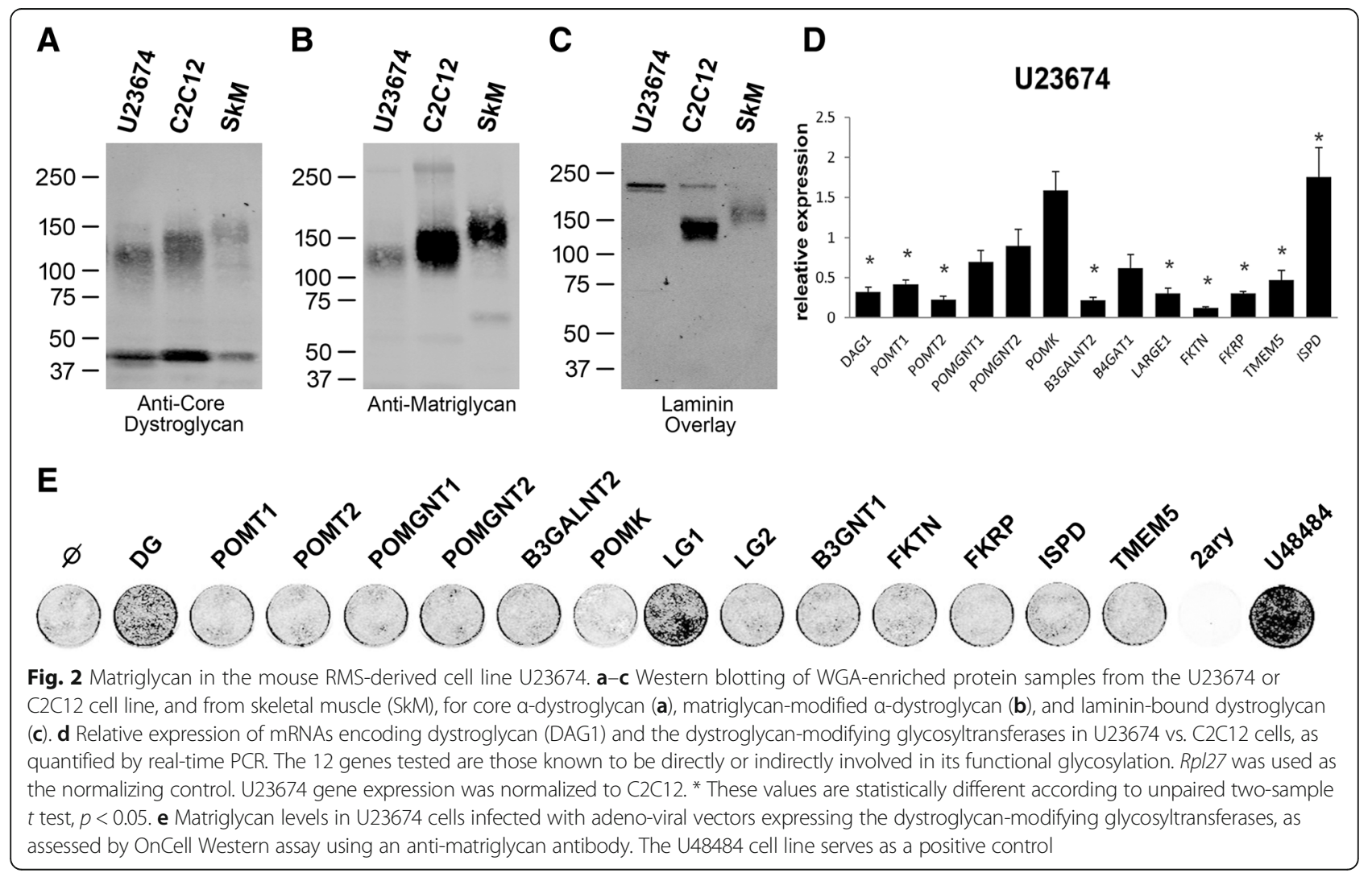


1:5000 dilution) followed by HRP-conjugated anti-rabbit IgG (Invitrogen, 1:5000 dilution). Plates were developed with o-phenylenediamine dihydrochloride and $\mathrm{H}_{2} \mathrm{O}_{2}$, and then reactions were stopped with $2 \mathrm{~N} \mathrm{H}_{2} \mathrm{SO}_{4}$. Absorbance per well was read at $490 \mathrm{~nm}$ by a microplate reader.

\section{Results}

A previous study showed a loss of fully glycosylated $\alpha$-dystroglycan in the majority of RMS samples from a small cohort; notably, the expression of $\beta$-dystroglycan, with which $\alpha$-dystroglycan is co-translated, was not significantly altered [18]. Since the publication of that work in 2007, our understanding of the intricate glycosylation and post-translational processing events required to synthesize the functional form of $\alpha$-dystroglycan has progressed significantly. In order to validate these results and expand the glycobiological analysis, we performed Western blotting using two distinct antibodies that recognize $\alpha$-dystroglycan: "anti-core dystroglycan," a polyclonal antibody that has specificity for epitopes along the backbones of both $\alpha$-dystroglycan and $\beta$-dystroglycan, and thus does not depend on glycosylation status; and monoclonal antibody IIH6 (antimatriglycan), which binds $\alpha$-dystroglycan only when it has been modified with matriglycan by LARGE [25]. The Western blot results are complemented by a laminin overlay assay, which measures the ability of $\alpha$-dystroglycan to bind laminin with high-affinity.

The first sample-set tested was the Children's Oncology Group Lookback tissue microarray (P1542), which includes both aRMS and eRMS subtypes. Nearly all eRMS and aRMS samples that were examined were negative for IIH6 staining, whereas normal skeletal muscle was positive (Fig. 1a-c). To determine whether the lack of matriglycan immunoreactivity in rhabdomyosarcomas reflects the loss of the core $\alpha$-dystroglycan protein or a defect in its processing, we next analyzed RMS tumors by immunoblotting. In all of the samples tested, bands representing both $\alpha$-dystroglycan (120$140 \mathrm{kDa})$ and $\beta$-dystroglycan $(\sim 43 \mathrm{kDa})$ were present (Fig. 1d). However, the two eRMS samples, as well as one of the aRMS samples, showed loss of both matriglycan immunoreactivity (Fig. 1e) and laminin binding (Fig. 1f). These results demonstrate that although the expression of dystroglycan is generally maintained in RMS tumors, the mature form of the protein is not always present.

We next sought to develop a cell culture model for biochemical and expression studies. We first tested a mouse aRMS cell line (U23674) for functional glycosylation of $\alpha$-dystroglycan and the expression of various enzymes involved in this process. We found that although

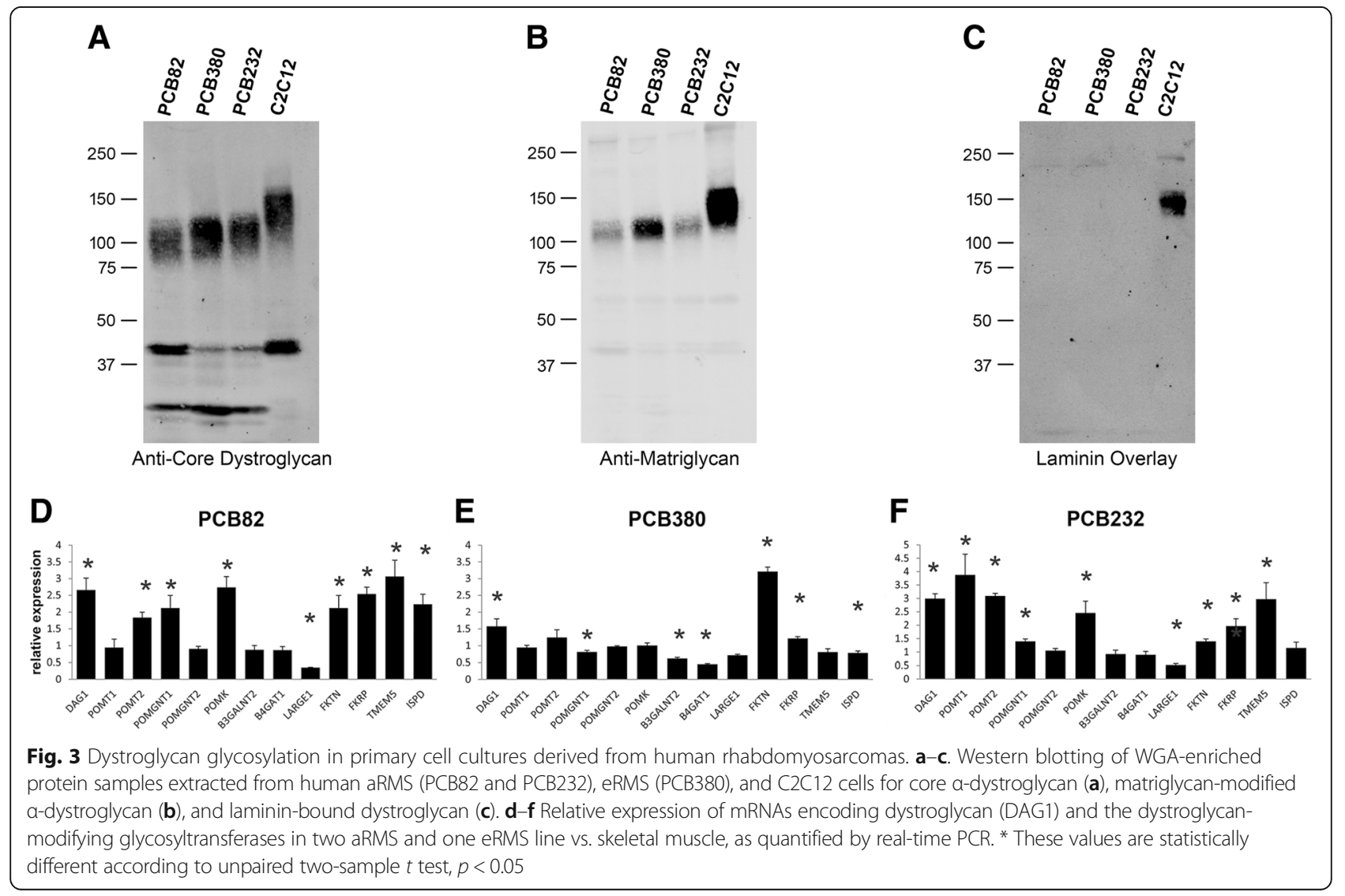


the amounts of $\alpha$-dystroglycan and $\beta$-dystroglycan in this line were similar to those in the $\mathrm{C} 2 \mathrm{C} 12$ normal muscle cell line and in mouse skeletal muscle (Fig. 2a), matriglycan immunoreactivity and laminin binding were lower than in both controls (Fig. 2b, c). Notably, comparing the expression of genes encoding glycosyltransferases that are known to modify $\alpha$-dystroglycan in the $\mathrm{U} 23674$ vs $\mathrm{C} 2 \mathrm{C} 12$ line did not reveal any changes large enough to explain the observed reduction in matriglycan immunoreactivity (Fig. 2d); based on our experience assessing changes in the expression of such genes in cell culture, only a reduction to $20 \%$ or less results in measurable $\alpha$-dystroglycan hypoglycosylation. Since we could not rule out the existence of inactivating mutations in any of these genes, we further tested U23674 cells for functional complementation by overexpressing individual glycosyltransferases. For this purpose, we infected these cells with adeno-viral vectors coding for each of the known $\alpha$-dystroglycan-modifying glycosyltransferases (individually) and tested the glycosylation status of $\alpha$-dystroglycan using the anti-matriglycan antibody. Of these, LARGE1 was the only gene tested whose

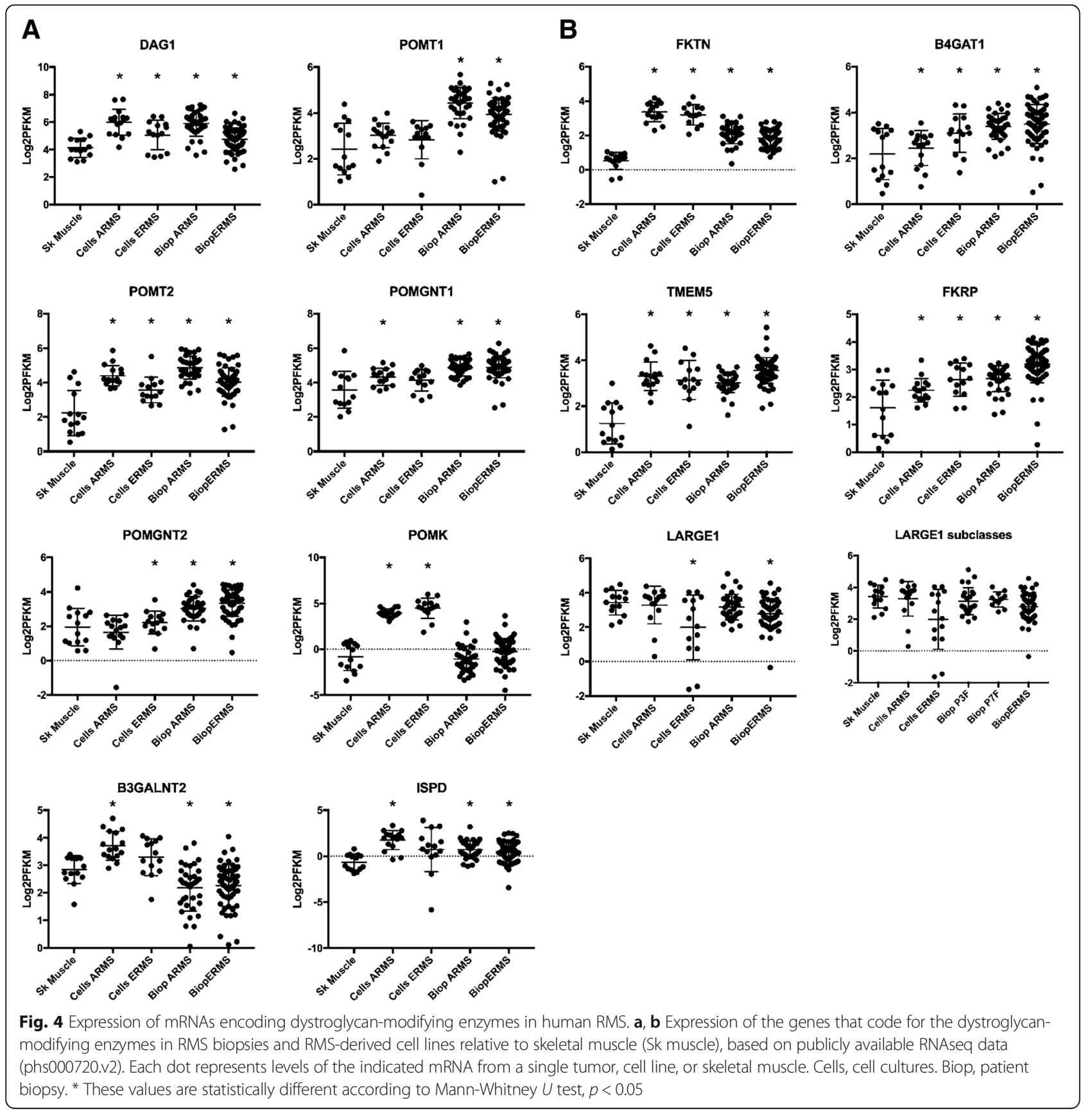


expression was able to restore matriglycan immunoreactivity (Fig. 2e).

We then analyzed two cell lines obtained from human eRMS tumors (PCB82 and PCB232) and one from an aRMS tumor (PCB380). All three cell lines produced bands that were detected by the anti-core dystroglycan antibody (Fig. 3a). However, matriglycan immunoreactivity was low compared to that in $\mathrm{C} 2 \mathrm{C} 12$ muscle cells (Fig. 3b) and laminin binding was nearly eliminated (Fig. 3c). The latter defect was especially pronounced in the two eRMS cell lines, PCB82 and PCB232. However, when RT-PCR analysis was used to compare expression of the glycosyltransferases in these three cell lines, no decreases in expression were sufficient to explain the reduced matriglycan immunoreactivity and laminin binding that were detected (Fig. 3d). Thus, unidentified factors seem to underlie the loss of $\alpha$-dystroglycan function in these cell lines.

We next interrogated a publicly available RNAseq dataset of RMS biopsies and cell lines [26] for expression of the genes known to be involved in the functional modification of $\alpha$-dystroglycan (Fig. 4a, b). Only two genes were downregulated at statistically significant levels in the RMS biopsy samples: B3GALNT2 and LARGE1. Whereas B3GALNT2 was downregulated in both ARMS and ERMS biopsies but not the corresponding cell lines, LARGE1 was downregulated specifically in the ERMS cells and biopsy samples. For further studies, we selected two highly utilized human RMS cell lines from this panel: Rh18 (eRMS), which expresses low levels of LARGE1; and Rh41 (aRMS), which expresses $L A R G E 1$ at normal levels. Analysis of both cell lines revealed that Rh18 is nearly devoid of functional $\alpha$-dystroglycan as reflected by a lack of matriglycan and by a loss of activity in the laminin overlay assay (Fig. 5a-c). Notably, these defects were accompanied by a nearly complete loss of $L A R G E 1$ expression (Fig. $5 \mathrm{~d}$ ).

Lastly, we tested whether ectopic expression of recombinant LARGE1 in Rh18 cells is sufficient to restore the modification of $\alpha$-dystroglycan with matriglycan. To this end, we transduced Rh18 cells with particles produced by an adeno-viral vector encoding LARGE1 (Ad-LG1) and compared the resulting cells to the parental
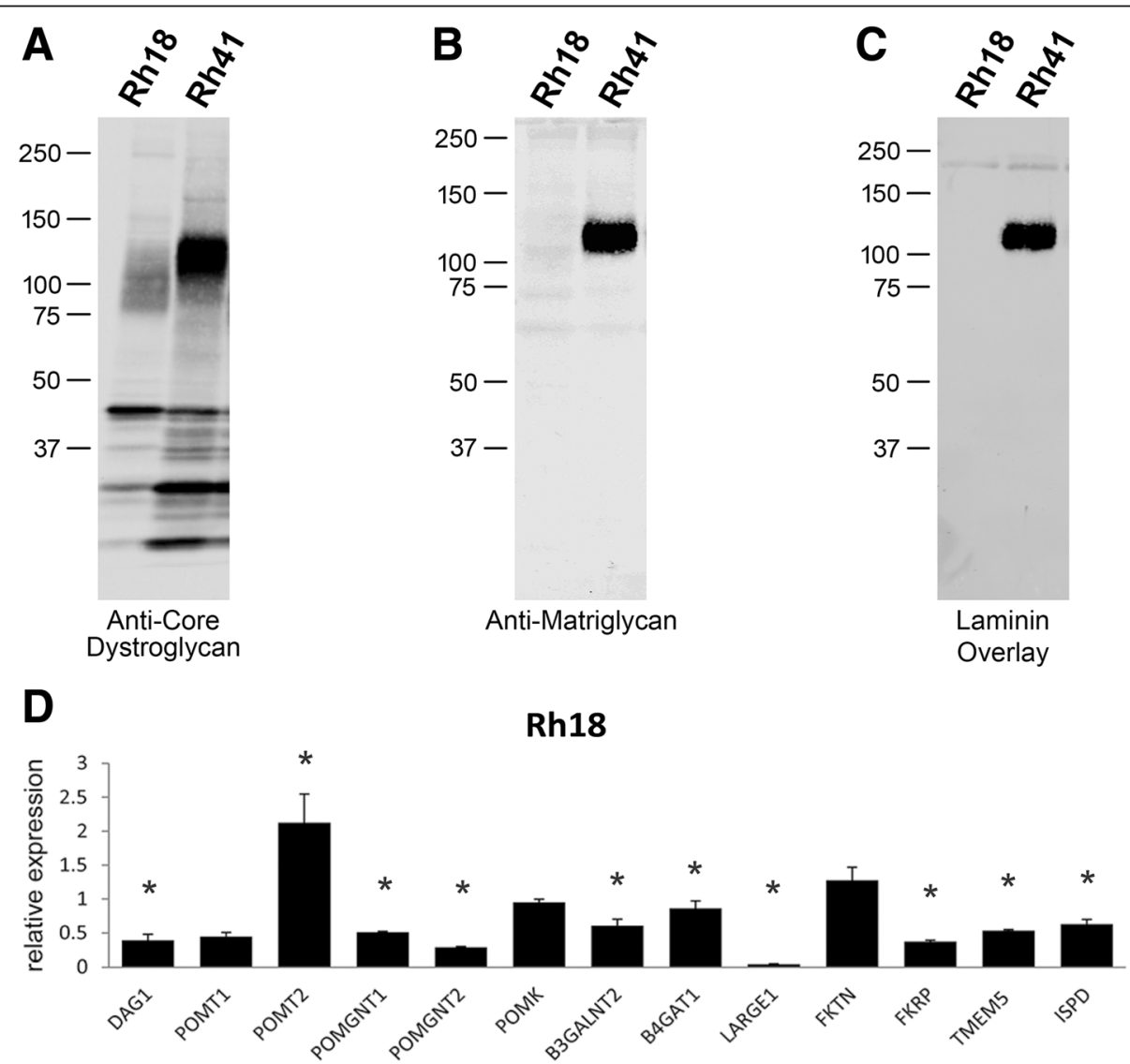

Fig. 5 Matriglycan levels in human eRMS and aRMS cell lines. a-c Western blotting of WGA-enriched protein samples extracted from the human eRMS cell line Rh18 and the aRMS cell line Rh41 for core a-dystroglycan (a), matriglycan-modified a-dystroglycan (b), and laminin-bound dystroglycan (c). d Relative expression of mRNAs encoding dystroglycan (DAG1) and the dystroglycan-modifying glycosyltransferases in the Rh18 cell line, as assessed by real-time PCR. * These values are statistically different according to unpaired two-sample $t$ test, $p<0.05$ 


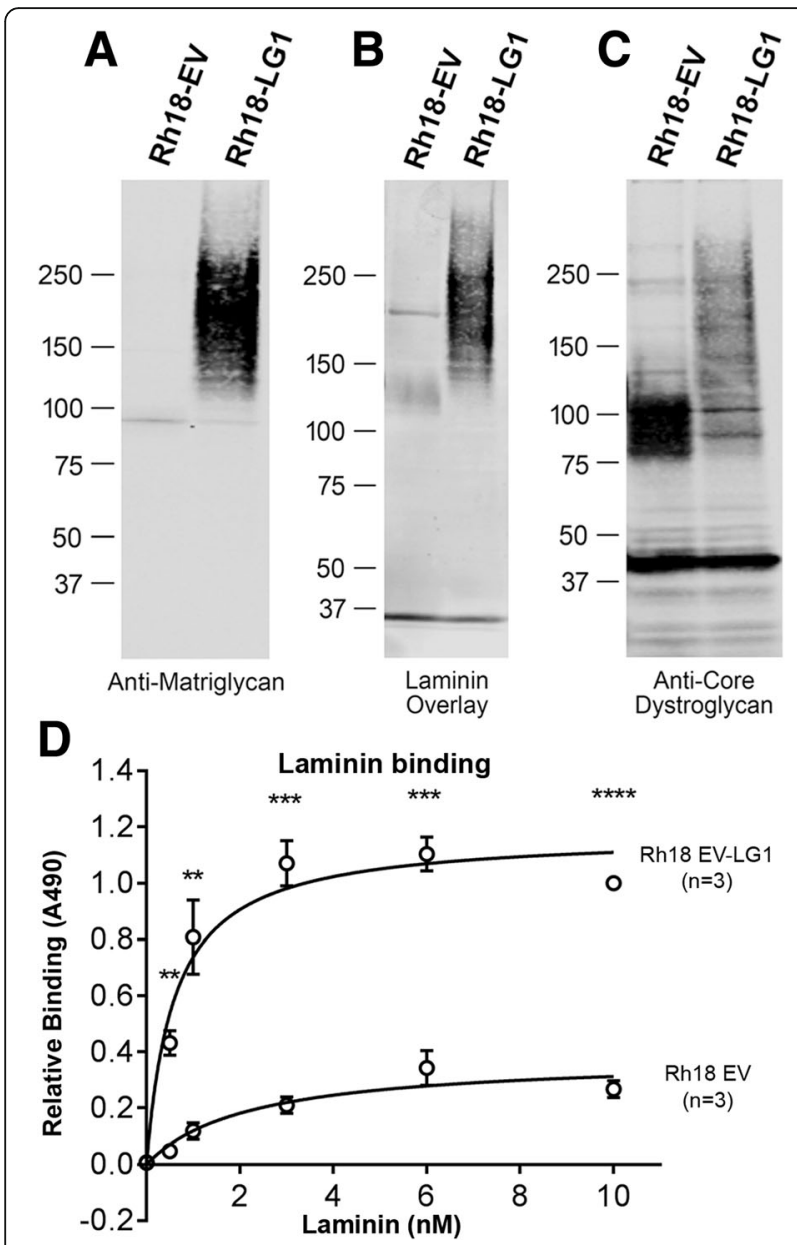

Fig. 6 Effects of LARGE1 expression in Rh18 cells. a-c Western blotting of the parent cell line (Rh18) and Rh18 cells transduced with particles produced by an adenovirus encoding LARGE1 for matriglycan-modified a-dystroglycan (a), laminin-bound dystroglycan (b), and core a-dystroglycan (c). d Laminin binding to Rh18 cells and Rh18 cells infected with adenovirus-expressing LARGE1. Error bars, s.e.m.; $n=3$, experimental replicate; ${ }^{* *} p<0.01$; ${ }^{* * *} p<0.001 ;{ }^{* * * *} p<0.0001$

(non-transduced) line (Fig. 6). We found that Rh18-LG1 cells produced a form of $\alpha$-dystroglycan whose $\mathrm{MW}$ $(150-200 \mathrm{kDa})$ (Fig. 6a) is similar to that in muscle and that $L A R G E 1$ overexpression restored both the addition of matriglycan onto $\alpha$-dystroglycan (Fig. 6a) and significantly restored its high-affinity laminin-binding function (Fig. 6b, d).

\section{Discussion}

The DGC plays a well-established role in the formation, function, and regeneration of skeletal muscle fibers. The importance of this complex is highlighted by the muscle pathology observed in individuals with germline mutations in the genes encoding components of this complex and the glycosyltransferases involved in the modification of $\alpha$-dystroglycan. Based on studies performed in both animal models and tumor samples, the DGC has also been suggested to contribute to the development of RMS $[17,18]$.

The first indication that the DGC might play a role in RMS was the high frequency of this type of tumor in mice deficient for $\alpha$-sarcoglycan and dystrophin, two central components of the DGC. In addition, a study of dystroglycan in pediatric cancers showed that $\alpha$-dystroglycan is misprocessed in a subset of human patients with RMS, although the exact mechanism was not determined [19]. In the current study, we have expanded on these findings by analyzing tumor samples and cell lines derived from mouse and human RMS. We show that both eRMS and aRMS tumors retain expression of the $\alpha$-dystroglycan and $\beta$-dystroglycan subunits, but that $\alpha$-dystroglycan is not modified with matriglycan, the heteropolysaccharide that confers its ligand-binding ability. Given that abnormal glycosylation has been observed in many other cancer types and is correlated with a poor prognosis [12-15], we extended this study to a series of cell lines derived from mouse and human RMS tumors. This revealed that the reduction in matriglycan levels is a common feature in cell lines derived from both mouse and human RMS.

In epithelium-derived cancers, downregulation of glycosyltransferase expression has been found to underlie abnormal glycosylation of $\alpha$-dystroglycan [14, 15, 27]. Strikingly, although a reduction in LARGE1 expression could account for the observed loss of matriglycan in particular, in certain RMS cases the collective decrease in the expression of several genes coding for $\alpha$-dystroglycan-modifying glycosyltransferases is substantial, although this decrease varies across tumor types. This heterogeneity is consistent with other factors affecting the functional glycosylation of $\alpha$-dystroglycan in RMS. On the other hand, ectopic expression of LARGE1 in cell lines that are characterized by a lack of matriglycan modification on $\alpha$-dystroglycan can restore both the modification (similar to levels in cell lines derived from skeletal muscle) and the ability of $\alpha$-dystroglycan to function as a laminin receptor.

We previously reported that $L A R G E 1$ is repressed in many epithelial cancer-derived cell lines, and showed that its ectopic expression reduces the invasiveness of such cells [13]. LARGE1 synthesizes and transfers repeating units of [-GlcA-beta1,3-Xyl-alpha1,3- $]_{n}$ onto $\alpha$-dystroglycan [28], forming the terminal glycan moiety anchored by the Core M3 structure on $\alpha$-dystroglycan. This structure resembles the ligand-binding glycan and its length correlates with the affinity of $\alpha$-dystroglycan for its ligands [25]. The fact that ectopic expression of LARGE1 restores the matriglycan modification in all of the RMS cell lines tested, irrespective of the internal levels of $L A R G E 1$, indicates that LARGE 1 restructures 
the binding of $\alpha$-dystroglycan so that it functions as an ECM receptor in RMS. Correspondingly, in the RMS cell line Rh18, ectopic expression of LARGE1 resulted in functional glycosylation of $\alpha$-dystroglycan and conferred its ability to bind laminin, its natural ligand, with high-affinity.

With respect to whether defects in the glycosylation of $\alpha$-dystroglycan might contribute to tumor initiation versus progression, it seems more likely that it is a secondary (somatic) event involved in tumor progression. After the metastatic cancer cell has reached its secondary site, it may restore LARGE1 expression in order to orchestrate the remodeling of the ECM in the growing secondary tumor. Although germline mutations in LARGE1 have been reported in a group of congenital muscular dystrophies that also involve brain and eye defects, no increase in the rate of any cancer type, including RMS, has been described in patients. However, these are rare diseases and the number of patients available for such studies is limited. Similarly, higher cancer rates have not been reported in patients who carry mutations in dystrophin or $\alpha$-sarcoglycan, two other components of the DGC that have been linked to RMS [18]. We reported that ectopic expression of LARGE1 in these cell lines enables cells to bind laminin and reduces the invasiveness of the phenotype. Recently, two other dystroglycan-modifying glycosyltransferases, LARGE2 and B4GALNT2, were linked with the cancer-associated abnormal glycosylation of $\alpha$-dystroglycan [14, 15]. Although the exact mechanisms underlying this phenotype are unknown, silencing of glycosyltransferase expression could play a role in some of these cancers. The current study is focused on establishing a proof of principle that LARGE1-driven loss of matriglycan is a common feature in rhabdomyosarcomas. Future studies will not only address the effect that matriglycan restoration may have on cell attachment and differentiation but also on in vivo invasion and metastasis.

\section{Conclusions}

We have demonstrated that the modification of $\alpha$-dystroglycan with matriglycan is dramatically reduced in a panel of RMS samples, and that this result is reproduced in RMS-derived cell lines. In some of the cell lines studied, the loss of matriglycan modifications could be attributed to the silencing of $L A R G E 1$ expression. This defect was reverted by ectopic expression of LARGE1 cDNA in all of the cell lines that were tested, which then showed normal levels of matriglycan modifications and restored the ability of $\alpha$-dystroglycan to bind to laminin. Thus, ectopic expression of LARGE1 may be worthy of further investigation as a potential therapeutic approach for RMS.

\author{
Abbreviations \\ aRMS: Alveolar rhabdomyosarcoma; CK: Creatine kinase; DGC: Dystrophin- \\ glycoprotein complex; DMD: Duchenne muscular dystrophy; \\ ECM: Extracellular matrix; eRMS: Embryonal rhabdomyosarcoma; \\ LARGE1: Like-acetylglucosaminyltransferase; RMS: Rhabdomyosarcoma
}

\section{Acknowledgements}

We are grateful to Amber Mower for assistance with technical illustration and to Drs. Christine Blaumueller and Jennifer Barr of the Scientific Editing and Research Communication Core at the University of lowa Carver College of Medicine for critical reading of the manuscript. We thank the Children's Oncology Group for tissue microarrays and the Viral Vector Core at the University of lowa for generating the adenoviruses.

\section{Funding}

This work was supported in part by a Paul D. Wellstone Muscular Dystrophy Cooperative Research Center grant (1U54NS053672 to KPC). KPC is an investigator of the Howard Hughes Medical Institute.

\section{Availability of data and materials}

All data generated or analyzed during this study are included in this published article.

\section{Authors' contributions}

DB co-designed the project, carried out the experimental work, analyzed and interpreted the data, and co-wrote the manuscript. TPS, MNS, and ZB codesigned the project, carried out the experimental work, and analyzed and interpreted the data. MEA, NB, JFS, SHG, MC, and TY carried out the experimental work and analyzed and interpreted the data. Corresponding authors CK and KPC co-designed the project, co-wrote the manuscript, and supervised the research. All authors contributed to critical review and revision of the manuscript. All authors read and approved the final manuscript.

\section{Ethics approval and consent to participate}

Muscle biopsies were originally collected for diagnostic purposes, at which time informed consent was obtained from all subjects or their legal guardians. The biopsies were collected and tested according to the guidelines set out by the Human Subjects Institutional Review Board.

\section{Consent for publication}

Not applicable.

Competing interests

The authors declare that they have no competing interests.

\section{Publisher's Note}

Springer Nature remains neutral with regard to jurisdictional claims in published maps and institutional affiliations.

\section{Author details}

${ }^{1}$ Department of Molecular Physiology and Biophysics, Department of Neurology, Howard Hughes Medical Institute, University of lowa Roy J. and Lucille A. Carver College of Medicine, 4283 Carver Biomedical Research Building, 285 Newton Road, lowa City, IA 52242-1101, USA. ${ }^{2}$ Children's Cancer Therapy Development Institute, 12655 SW Beaverdam Road W, Beaverton, OR 97005, USA. ${ }^{3}$ Pediatric Oncology Branch, Center for Cancer Research, National Institutes of Health, Bethesda, MD 20892, USA.

${ }^{4}$ Department of Pathology, Oregon Health \& Science University, Portland, OR 97239, USA.

Received: 19 November 2018 Accepted: 9 April 2019

Published online: 04 May 2019

\section{References}

1. Barresi R, Campbell KP. Dystroglycan: from biosynthesis to pathogenesis of human disease. J Cell Sci. 2006;119(Pt 2):199-207.

2. Durbeej M, Campbell KP. Muscular dystrophies involving the dystrophinglycoprotein complex: an overview of current mouse models. Curr Opin Genet Dev. 2002;12(3):349-61. 
3. Yamada H, Denzer AJ, Hori H, Tanaka T, Anderson LV, Fujita S, et al. Dystroglycan is a dual receptor for agrin and laminin-2 in Schwann cell membrane. J Biol Chem. 1996;271(38):23418-23.

4. Kanagawa M, Saito F, Kunz S, Yoshida-Moriguchi T, Barresi R, Kobayashi YM, et al. Molecular recognition by LARGE is essential for expression of functional dystroglycan. Cell. 2004;117(7):953-64.

5. Kunz S, Sevilla N, McGavern DB, Campbell KP, Olstone MB. Molecular analysis of the interaction of LCMV with its cellular receptor a-dystroglycan. J Cell Biol. 2001;155(2):301-10.

6. Gee SH, Montanaro F, Lindenbaum MH, Carbonetto S. Dystroglycan-alpha, a dystrophin-associated glycoprotein, is a functional agrin receptor. Cell. 1994 77(5):675-86.

7. Talts JF, Andac Z, Gohring W, Brancaccio A, Timpl R. Binding of the G domains of laminin alpha1 and alpha2 chains and perlecan to heparin, sulfatides, alpha-dystroglycan and several extracellular matrix proteins. EMBO J. 1999;18(4):863-70.

8. Wright KM, Lyon KA, Leung H, Leahy DJ, Ma L, Ginty DD. Dystroglycan organizes axon guidance cue localization and axonal pathfinding. Neuron. 2012;76(5):931-44.

9. Ilsley JL, Sudol M, Winder SJ. The WW domain: linking cell signalling to the membrane cytoskeleton. Cell Signal. 2002;14(3):183-9.

10. Yang B, Jung D, Motto D, Meyer J, Koretzky G, Campbell KP. SH3 domainmediated interaction of dystroglycan and Grb2. J Biol Chem. 1995;270(20): 11711-4.

11. Spence HJ, Dhillon AS, James M, Winder SJ. Dystroglycan, a scaffold for the ERK-MAP kinase cascade. EMBO Rep. 2004;5(5):484-9.

12. Henry MD, Cohen MB, Campbell KP. Reduced expression of dystroglycan in breast and prostate cancer. Hum Pathol. 2001;32(8):791-5.

13. Sgambato A, Migaldi M, Montanari M, Camerini A, Brancaccio A, Rossi G, et al. Dystroglycan expression is frequently reduced in human breast and colon cancers and is associated with tumor progression. Am J Pathol. 2003; 162(3):849-60

14. de Bernabe DB, Inamori K, Yoshida-Moriguchi T, Weydert CJ, Harper HA, Willer $\mathrm{T}$, et al. Loss of alpha-dystroglycan laminin binding in epitheliumderived cancers is caused by silencing of LARGE. J Biol Chem. 2009;284(17): 11279-84.

15. Esser AK, Miller MR, Huang Q, Meier MM, Beltran-Valero de Bernabe D, Stipp CS, et al. Loss of LARGE2 disrupts functional glycosylation of alphadystroglycan in prostate cancer. J Biol Chem. 2013;288(4):2132-42.

16. Bao X, Kobayashi M, Hatakeyama S, Angata K, Gullberg D, Nakayama J, et al. Tumor suppressor function of laminin-binding alpha-dystroglycan requires a distinct beta3-N-acetylglucosaminyltransferase. Proc Natl Acad Sci U S A. 2009;106(29):12109-14

17. Fernandez K, Serinagaoglu Y, Hammond S, Martin LT, Martin PT. Mice lacking dystrophin or alpha sarcoglycan spontaneously develop embryonal rhabdomyosarcoma with cancer-associated p53 mutations and alternatively spliced or mutant Mdm2 transcripts. Am J Pathol. 2010;176(1):416-34.

18. Martin LT, Glass M, Dosunmu E, Martin PT. Altered expression of natively glycosylated alpha dystroglycan in pediatric solid tumors. Hum Pathol. 2007; 38(11):1657-68.

19. Wang Y, Marino-Enriquez A, Bennett RR, Zhu M, Shen Y, Eilers G, et al. Dystrophin is a tumor suppressor in human cancers with myogenic programs. Nat Genet. 2014;46(6):601-6.

20. Taniguchi E, Nishijo K, McCleish AT, Michalek JE, Grayson MH, Infante AJ, et al. PDGFR-A is a therapeutic target in alveolar rhabdomyosarcoma. Oncogene. 2008;27(51):6550-60.

21. Aslam MI, Abraham J, Mansoor A, Druker BJ, Tyner JW, Keller C. PDGFRbeta reverses EphB4 signaling in alveolar rhabdomyosarcoma. Proc Natl Acad Sci U S A. 2014;111(17):6383-8.

22. Briggs DC, Yoshida-Moriguchi T, Zheng T, Venzke D, Anderson ME, Strazzulli A, Moracci M, Yu L, Hohenester E, Campbell KP. Structural basis of laminin binding to the LARGE glycans on dystroglycan. Nat Chem Biol. 2016;12(10): 810-4.

23. Michele DE, Barresi R, Kanagawa M, Saito F, Cohn RD, Satz JS, Dollar H, Nishino I, Kelley RI, Somer H, Straub V, Mathews KD, Moore SA, Campbell KP. Post-translational disruption of dystroglycan-ligand interactions in congenital muscular dystrophies. Nature. 2002;418(6896):417-22.

24. Briggs D, Yoshida-Moriguchi T, Zheng T, Venzke D, Anderson M, Strazzulli A, Moracci M, Yu L, Hohenester E, Campbell KP. Structural basis of laminin binding to the LARGE glycans on dystroglycan. Nat Chem Biol. 2016;12(10): 810-4.
25. Goddeeris MM, Wu B, Venzke D, Yoshida-Moriguchi T, Saito F, Matsumura K, et al. LARGE glycans on dystroglycan function as a tunable matrix scaffold to prevent dystrophy. Nature. 2013;503(7474):136-40.

26. Shern JF, Chen L, Chmielecki J, Wei JS, Patidar R, Rosenberg M, et al. Comprehensive genomic analysis of rhabdomyosarcoma reveals a landscape of alterations affecting a common genetic axis in fusion-positive and fusion-negative tumors. Cancer Discov. 2014;4(2):216-31.

27. Miller MR, Ma D, Schappet J, Breheny P, Mott SL, Bannick N, et al. Downregulation of dystroglycan glycosyltransferases LARGE2 and ISPD associate with increased mortality in clear cell renal cell carcinoma. Mol Cancer. 2015;14:141.

28. Inamori K, Hara Y, Willer T, Anderson ME, Zhu Z, Yoshida-Moriguchi T, et al. Xylosyl- and glucuronyltransferase functions of LARGE in alpha-dystroglycan modification are conserved in LARGE2. Glycobiology. 2013;23(3):295-302.
Ready to submit your research? Choose BMC and benefit from:

- fast, convenient online submission

- thorough peer review by experienced researchers in your field

- rapid publication on acceptance

- support for research data, including large and complex data types

- gold Open Access which fosters wider collaboration and increased citations

- maximum visibility for your research: over $100 \mathrm{M}$ website views per year

At BMC, research is always in progress.

Learn more biomedcentral.com/submissions 